\title{
Cognitive Factors Modulate Activity within the Human Subthalamic Nucleus during Voluntary Movement in Parkinson's Disease
}

\author{
Ashwini Oswal, ${ }^{1,2}$ Vladimir Litvak, ${ }^{2}$ Christof Brücke, ${ }^{3}$ Julius Huebl, ${ }^{3}$ Gerd-Helge Schneider, ${ }^{4}$ Andrea A. Kühn, ${ }^{3}$ \\ and Peter Brown ${ }^{1}$ \\ ${ }^{1}$ Nuffield Department of Clinical Neurosciences, John Radcliffe Hospital, Oxford OX9 3DU, United Kingdom, ${ }^{2}$ Wellcome Trust Centre for Neuroimaging, \\ London WC1N 3BG, United Kingdom, and ${ }^{3}$ Department of Neurology, ${ }^{4}$ Department of Neurosurgery, Charité-University Medicine Berlin, 10177 Berlin, \\ Germany
}

Movement is accompanied by changes in the degree to which neurons in corticobasal ganglia loops synchronize their activity within discrete frequency ranges. Although two principal frequency bands - beta $(15-30 \mathrm{~Hz})$ and gamma $(60-90 \mathrm{~Hz})$ - have been implicated in motor control, the precise functional correlates of their activities remain unclear. Local field potential (LFP) recordings in humans with Parkinson's disease undergoing surgery for deep brain stimulation to the subthalamic nucleus (STN) indicate that spectral changes both anticipate movement and occur perimovement. The extent to which such changes are modulated by cognitive factors involved in making a correct response seems critical in characterizing the functional associations of these oscillations. Accordingly, by recording LFP activity from the STN in parkinsonian patients, we demonstrate that perimovement beta and gamma reactivity is modulated by task complexity in a dopamine-dependent manner, despite the dynamics of the movement remaining unchanged. In contrast, spectral changes occurring in anticipation of future movement were limited to the beta band and, although modulated by dopaminergic therapy, were not modulated by task complexity. Our findings suggest two dopamine-dependent processes indexed by spectral changes in the STN: (1) an anticipatory activity reflected in the beta band that signals the likelihood of future action but does not proactively change with the cognitive demands of the potential response, and (2) perimovement activity that involves reciprocal beta and gamma band changes and is not exclusively related to explicit motor processing. Rather perimovement activity can also vary with, and may reflect, the cognitive complexity of the task.

\section{Introduction}

Synchronized oscillations in the beta and gamma frequency bands are thought to play a role in motor control in corticobasal ganglia motor loops (Brown, 2006). The opportunity to record such activity in humans sometimes arises in patients with Parkinson's disease undergoing surgery for therapeutic deep brain stimulation (DBS), where the commonest target is the subthalamic nucleus (STN; Ponce and Lozano, 2010). STN local field potential (LFP) activity in the beta band is suppressed for several seconds before self-paced voluntary movement and following cues salient to forthcoming movement (Williams et al., 2003; Alegre et

Received April 29, 2013; revised Aug. 13, 2013; accepted Aug. 16, 2013.

Author contributions: C.B., J.H., A.A.K., and P.B. designed research; C.B., J.H., and G.-H.S. performed research; A.O., V.L., A.A.K., and P.B. contributed unpublished reagents/analytic tools; A.O. analyzed data; A.O., V.L., A.A.K., and P.B. wrote the paper.

This work was supported by the Medical Research Council and the National Institute for Health Research Oxford Biomedical Research Centre. A.A.K. was support by a grant of the German Research Foundation (DFG KF0247).

The authors declare no competing financial interests.

This article is freely available online through the J Neurosci Author Open Choice option.

Correspondence should be addressed to Peter Brown, Professor of Experimental Neurology, Nuffield Department

of Clinical Neurosciences, University of Oxford, Level 6, West Wing, John Radcliffe Hospital, Oxford OX3 9DU, UK. E-mail: peter.brown@ndcn.ox.ac.uk.

DOI:10.1523/JNEUROSCI.1790-13.2013

Copyright $\odot 2013$ the authors $\quad 0270-6474 / 13 / 3315815-12 \$ 15.00 / 0$ al., 2005; Androulidakis et al., 2008; Oswal et al., 2012). However, the extent to which such anticipatory changes in beta activity are modulated by contextual factors, like reward, and by the need to resource more challenging responses remains unclear. Moreover, beta activity in the STN is further suppressed around the time of movement, suggesting that it might not only relate to anticipatory processes but also to the processing of movement (Brown, 2006; Hammond et al., 2007). In addition, reciprocal increases in gamma band synchronization are seen in the STN during this perimovement period and have likewise been related to the processing of movement (Cassidy et al., 2002; Williams et al., 2002; Alegre et al., 2005; Foffani et al., 2005; Fogelson et al., 2005; Alonso-Frech et al., 2006; Devos et al., 2006; Trottenberg et al., 2006; Androulidakis et al., 2008). Although it is unclear what features are encoded by these reciprocal changes, one possibility is that perimovement spectral changes in the STN, particularly those in the gamma band, encode response force or, related to this, movement speed (Anzak et al., 2012; Brücke et al., 2012, 2013; Joundi et al., 2012; Tan et al., 2013a). This would place perimovement spectral changes in the STN at the executive end of processing and disassociate them from any link to the representation of action values thought to be important elsewhere in the basal ganglia (Samejima et al., 2005). Alternatively, they may 
Table 1. Clinical characteristics of the patients recorded

\begin{tabular}{|c|c|c|c|c|c|c|c|}
\hline Case & $\begin{array}{l}\text { Age (years) } \\
\text { and sex }\end{array}$ & $\begin{array}{l}\text { Disease dura- } \\
\text { tion (years) }\end{array}$ & $\begin{array}{l}\text { Unified Parkinson's Disease } \\
\text { Rating Scale III off/on drug }\end{array}$ & $\begin{array}{l}\text { Daily medication } \\
(\mathrm{mg})\end{array}$ & $\begin{array}{l}\text { First recording (days } \\
\text { postoperation) }\end{array}$ & Order of recordings & $\begin{array}{l}\text { Test dose } \\
\text { levodopa }(\mathrm{mg})\end{array}$ \\
\hline 1 & $51 \mathrm{M}$ & 13 & $48 / 32$ & LDE 900 & 2 & On 1/off 2 & 200 \\
\hline 2 & $26 \mathrm{M}$ & 10 & $40 / 15$ & LDE 400 & 2 & On $1 /$ off 2 & 100 \\
\hline 3 & $53 \mathrm{M}$ & 15 & $48 / 18$ & LDE 1300 & 2 & On $1 /$ off 2 & 100 \\
\hline 4 & $62 \mathrm{M}$ & 9 & $28 / 5$ & LDE 2500 & 3 & Off $1 /$ on 2 & 200 \\
\hline 5 & $56 \mathrm{M}$ & 15 & $31 / 9$ & LDE 750 & 6 & On 1/off 2 & 100 \\
\hline 6 & $53 \mathrm{M}$ & 8 & $16 / 9$ & LDE 1100 & 5 & Off $1 /$ on 2 & 100 \\
\hline 7 & $59 \mathrm{~F}$ & 16 & $26 / 9$ & LDE 1150 & 3 & $\begin{array}{l}\text { Off } 1 / \text { on } 2 \text {; only on used } \\
\text { off } 1 / \text { on } 2 \text {, but unable to } \\
\text { perform task off due }\end{array}$ & 200 \\
\hline 8 & $51 \mathrm{M}$ & 19 & $40 / 7$ & LDE 1850 & 4 & $\begin{array}{l}\text { to severe tremor } \\
\text { off } 1 / \text { on } 2 \text {, but unable to } \\
\text { perform task off due }\end{array}$ & 100 \\
\hline 9 & $49 \mathrm{~F}$ & 10 & $41 / 8$ & LDE 900 & 4 & to severe tremor & 100 \\
\hline
\end{tabular}

LDE, Levodopa dose equivalent.

relate to higher-order phenomena, such as the cognitive or motor effort to be exerted in an action that is then organized elsewhere (Mazzoni et al., 2007; Niv and Rivlin-Etzion, 2007; Salamone et al., 2009; Turner and Desmurget, 2010). Again, the extent to which perimovement spectral changes in the STN are modulated by contextual factors, such as potential reward, and by task complexity would seem to be critical information in characterizing the functional associations of these oscillations. Specifically, modulation by these contextual factors might help disambiguate whether cognitive demands, and not just force, might be encoded by perimovement spectral changes in the STN.

Here we explore the modulation of both anticipatory and perimovement spectral changes in the STN by potential reward and task complexity, while also considering whether dopaminergic state is an important factor in any such modulation. Task complexity was isolated from movement dynamics (which remained similar) through the performance of movements in which the spatial mapping between the cued limb and the limb required to be moved was either compatible or incompatible.

\section{Materials and Methods}

Nine patients (seven male and two female) with idiopathic Parkinson's disease who underwent implantation of DBS electrodes in the STN at two surgical centers participated in the study. All procedures were approved by the local ethics committees at the two surgical centers. The clinical characteristics of the patients are shown in Table 1. Each was implanted bilaterally for the treatment of their Parkinson's disease. All patients gave informed written consent to participate in the study, which was approved by the local ethics committees. The DBS electrode used was model 3389 (Medtronic Neurological Division) with four platinum-iridium cylindrical surfaces ( $1.27 \mathrm{~mm}$ diameter and $1.5 \mathrm{~mm}$ length) and a contact-tocontact separation of $0.5 \mathrm{~mm}$. Contact 0 was the most caudal and contact 3 was the most rostral. Electrode implantation was performed according to the standard procedures of each surgical center. The intended coordinates for STN were $12 \mathrm{~mm}$ lateral from the midline, $3 \mathrm{~mm}$ behind the midcommissural point, and $\sim 4 \mathrm{~mm}$ below the anterior commissureposterior commissure line. Adjustments to the intended surgical coordinates were made according to the direct visualization of STN on individual preoperative stereotactic T2-weighted magnetic resonance imaging (MRI), intraoperative stimulation, and, in all but one case, intraoperative microelectrode recordings. Postoperative MRI was performed in all patients to confirm targeting and suggested that at least one contact was within the STN. None of the patients had any surgical complications, postoperative confusion, or severe motor impairment that precluded understanding or performance of the test, at least while on medication.
Paradigm. We developed a paradigm that separated the processing of information relating to the warning of the reward or complexity of an upcoming task from the processing of the specific motor response. This was achieved by presenting a warning cue that signaled whether an upcoming stimulus-response pairing was either compatible or incompatible (signaled by a gold or gray arrow, respectively) and also whether correct subsequent motor performance was to be highly or lowly rewarded (signaled by a gold or gray coin; Fig. 1). Consequently there were four different types of warning cue, each corresponding to a different trial condition, which was presented with equal probability. The warning cue was followed by an imperative cue, which comprised a schematic of the body with a single segment highlighted in red (right hand, left hand, right foot, or left foot with equal probability). Temporal expectancy of the imperative cue was limited by pseudorandomization of the intercue interval. A fixed reward of $€ 12$ or $£ 10$ per drug session was given on completion of the whole experiment, although subjects were told at the outset of the experiment that reward depended in an undisclosed manner on performance during the recordings. This subterfuge that reward was not in the end scaled to performance was to avoid discriminating between patients according to disease severity or ability and was agreed by the local ethics committee. Accordingly, patients were not given trial-to-trial feedback on the level of award accrued, although this may have undermined the impact of reward blocks.

Crucially the required movement was dependent both on the cued limb and on the information about task complexity in the initial warning cue. In the case of the warning cue indicating an upcoming task of low complexity, imperative stimulus and response were compatible and subjects were instructed to move the cued limb. However, in the case of the warning cue indicating an upcoming task of high complexity, subjects were instructed to move the diagonally opposite limb. Thus the subsequent imperative cue and response were incompatible. In this way, the correct execution of the two stimulus-response compatibility conditions necessitated direct and indirect visuomotor transformations, respectively. If the required movement was a hand movement, subjects were required to make a button press with the index finger of the corresponding hand, while in the case of foot movements, subjects were asked to dorsiflex the ankle joint. Consequently, for each of the two levels of task complexity, the final movements of each limb would be similar across the blocks (although the response times might differ). Thus, the cognitive processes required in the low-complexity and high-complexity trials differed due to their contrasting stimulus-response compatibilities, despite the effect that on average movements did not differ across blocks.

The experiment began with some demonstration trials in which the intended movements were shown to the patient while they were seated comfortably in a chair. Subjects were instructed to concentrate on accuracy and speed before the start of the blocks. The experiment was performed in up to four blocks in each medication (on/off) condition (each block containing six trials of each type in pseudorandomized order). 


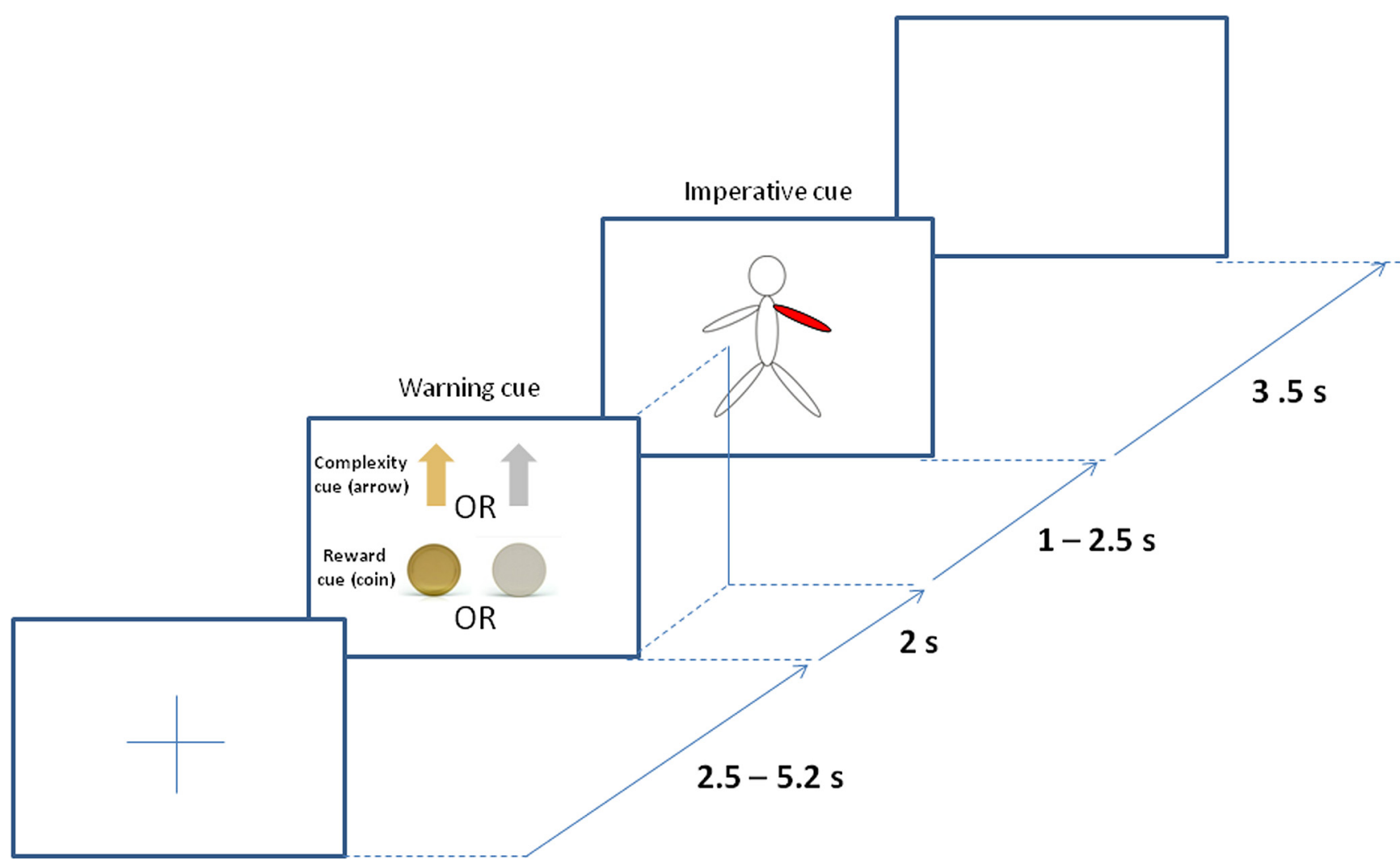

Figure 1. Schematic of a typical trial: a warning cue with an arrow and coin signaled the complexity and reward of an upcoming trial. The presentation of a gold or gray arrow instructed high or low trial complexity, while the presentation of a gold or gray coin signaled high or low reward, respectively. Patients were instructed to move the highlighted body segment only when the warning cue signaled low trial complexity. In the case of a warning cue signaling high trial complexity, patients were instructed to move the limb diagonally opposite to the limb highlighted in red. For example, in high-complexity trials, if the left arm was highlighted, the correct response would be to move the right leg.

Table 2. Number of correctly performed trials recorded from each patient in each of the four different conditions on and off levodopa ${ }^{a}$

\begin{tabular}{|c|c|c|c|c|c|c|c|c|}
\hline \multirow[b]{2}{*}{ Case } & \multicolumn{4}{|c|}{ On medication } & \multicolumn{4}{|c|}{ Off medication } \\
\hline & HRLC & LRLC & HRHC & LRHC & HRLC & LRLC & HRHC & LRHC \\
\hline 1 & $22(24)$ & $22(24)$ & $24(24)$ & $22(24)$ & $21(24)$ & $23(24)$ & $24(24)$ & $20(24)$ \\
\hline 2 & $20(24)$ & $23(24)$ & $20(24)$ & 19 (24) & 14 (24) & $19(24)$ & $18(24)$ & 18 (24) \\
\hline 3 & 24 (24) & 24 (24) & $24(24)$ & $20(24)$ & 15 (18) & $16(18)$ & 16 (18) & 15 (18) \\
\hline 4 & $12(18)$ & $12(18)$ & $11(18)$ & $12(18)$ & 15 (18) & 18 (18) & $16(18)$ & $18(18)$ \\
\hline 5 & 24 (24) & $20(24)$ & $24(24)$ & $24(24)$ & 10 (18) & $8(18)$ & $8(18)$ & $6(18)$ \\
\hline 6 & $20(24)$ & 19 (24) & 19 (24) & $20(24)$ & 24 (24) & $24(24)$ & 24 (24) & 24 (24) \\
\hline 7 & 18 (24) & 18 (24) & $18(24)$ & $20(24)$ & - & - & - & - \\
\hline 8 & $24(24)$ & $22(24)$ & $23(24)$ & $23(24)$ & - & - & - & - \\
\hline 9 & $8(12)$ & $8(12)$ & $12(12)$ & $3^{b}(12)$ & - & - & - & - \\
\hline
\end{tabular}

${ }^{a}$ Figures in parentheses indicate total number of trials recorded from each patient and each condition.

${ }^{b}$ Condition rejected because the proportion of correctly performed trials $(\leq 25 \%)$ corresponded to randomly chosen movement.

HRLC, High reward and low complexity; LRLC, low reward and low complexity; HRHC, high reward and high complexity; LRHC, low reward and high complexity.

Blocks lasted $4 \mathrm{~min}$, and were followed by 1-2 min rest. Each block consisted of 24 trials. The majority of patients were able to perform all four blocks. However, some were only able to perform two or three blocks, giving a total number of 12-24 trials per condition. Each trial started with the presentation of a fixation cross at the center of a PC screen (Fig. 1), followed 2.5-5.2 s later by a warning cue of fixed duration $(2 \mathrm{~s})$. The onset of the warning cue was followed by a period of $3-4.5 \mathrm{~s}$, before the imperative cue of a body schema, which was presented for $3.5 \mathrm{~s}$. This was followed by a blank screen for $1 \mathrm{~s}$, before the next trial began with reappearance of the fixation cross. The fixation cross, warning, and imperative cues were centered around the middle of the screen so as to limit confounding eye movements. The total duration of the recordings made on and off medication was $\sim 1 \mathrm{~h}$.

Patients were kept under constant visual inspection by the researcher and error trials noted. Error trials consisted of the patient moving the wrong body part. We excluded these trials from subsequent analysis, as we could not be sure of whether the subject had attended to either the warning cue or the imperative cue. The number of trials accepted for each subject and condition is shown in Table 2. Furthermore, we deleted blocks of trials with less than a number of trials corresponding to a random choice probability (25\%) of moving the four body limbs.

Recordings. Patients were studied 2-6d postoperatively, in the interval between electrode implantation and subsequent connection to a subcutaneous stimulator. Of these, four patients were first assessed on medication and then off medication on the following day, and the other five were assessed first off then on medication. However, only six of the patients were able to perform/complete the task off medication. Offmedication recordings were performed after overnight withdrawal of antiparkinsonian medication (Table 1). On-medication recordings were performed $1 \mathrm{~h}$ after the usual morning dose of antiparkinsonian medi- 
cation or levodopa (100 mg), whichever was higher, and were achieved in all subjects.

Surface EMG was recorded from tibialis anterior bilaterally in each patient. LFPs, EMG and analog signals related to the cues, and button presses were recorded using a D360 amplifier (Digitimer) in combination with a 1401 analog-to-digital converter (Cambridge Electronic Design) and sampled onto a computer using Spike2 V6 software (Cambridge Electronic Design). LFP activity was recorded bipolarly from the four contacts $(01,12$, and 23 , in which contact pair 01 was the most caudal) of each DBS electrode targeting the STN, amplified (50,000 $)$, filtered $(1.0-1000 \mathrm{~Hz})$, and sampled at a common rate of $5000 \mathrm{~Hz}$. EMGs were amplified $(1000 \times)$ and filtered $(10-1000 \mathrm{~Hz})$, before being sampled at the above rate.

Spectral analysis. The data were analyzed in Matlab (Mathworks) for subsequent analysis using custom scripts and the FieldTrip (http://www. ru.nl/neuroimaging/fieldtrip/) and SPM8 (http://www.fil.ion.ucl.ac. $\mathrm{uk} / \mathrm{spm} /$ ) toolboxes (Litvak et al., 2011; Oostenveld et al., 2011). EMGs were high-pass filtered at $10 \mathrm{~Hz}$ and the absolute value of the Hilbert transform of the resulting signal was taken (Kilner et al., 2000; Schoffelen et al., 2011), before smoothing with a $1 \mathrm{~s}$ boxcar function. The resulting signal was standardized by $z$ transformation and movement onset was defined as the point at which the $z$ score exceeded 0.5 (http://fieldtrip. fcdonders.nl/example/detect_the_muscle_activity_in_an_emg_channel_ and_use_that_as_trial_definition). This $z$ threshold was used for all subjects and was visually confirmed to correspond to the onset of EMG activity for all trials. The time of onset of movement in the upper limb was determined by the timing of button presses. Data were epoched into trials, excluding trials with errors. Subsequently, the average LFP signal over all correct trials was removed from the LFP signal of each individual trial to generate the induced response. Spectral analysis was performed using the multitaper method for each bipolar electrode pair for all subjects (Thomson, 1982). The resulting spectra were averaged across all the contact pairs in a given electrode that had $\geq 1$ contact in the STN as independently assessed by an experienced neurosurgeon or neurologist specializing in DBS who was blinded to the electrophysiological data. Contact classification was performed from perioperative MRI imaging, as detailed above.

Spectral analysis was performed for each trial of each of the four conditions, on and off medication in each subject. We analyzed spectra in overlapping windows of $400 \mathrm{~ms}$, shifted by $50 \mathrm{~ms}$. The frequency resolution was set to the inverse of the time window $(2.5 \mathrm{~Hz})$ for up to $25 \mathrm{~Hz}$, then 0.1 times the frequency for $25-50 \mathrm{~Hz}$ and then to a constant $5 \mathrm{~Hz}$ resolution. These settings resulted in a single taper being used for 2.5-30 $\mathrm{Hz}$, two tapers for $32.5-42.5 \mathrm{~Hz}$, and three tapers for $\geq 45 \mathrm{~Hz}$. The resulting time-frequency images had no discontinuities thanks to the continuous frequency resolution function.

The trial power data were first normalized to a baseline $(-0.8-0 \mathrm{~s})$ before the warning cue to obtain percentage changes, before averaging using robust averaging (regardless of the body part highlighted by the imperative cue). This was performed for each subject across the different conditions ( $\leq 8$ in total, as documented in Table 2 , and drawn from $\leq 4$ blocks of trials on and $\leq 4$ blocks off medication). The benefits of robust averaging for increasing the signal-to-noise ratio in data with low trial numbers have been previously demonstrated (Litvak et al., 2012; Oswal et al., 2013). In essence, robust averaging is a special case of the robust general linear model (Wager et al., 2005). The idea is that for each timefrequency bin, the distribution of values over trials is considered and outliers are down-weighted when computing the average, thereby affording improved immunity to high-power artifacts.

Statistics. We first compared response times of subjects in the eight conditions. For statistical analysis we analyzed reciprocal response times, since they are known to have an approximate normal distribution, hence facilitating parametric statistical testing procedures (Carpenter and Williams, 1995). Reciprocal response times were then averaged for each condition in each subject. We were not interested in response time differences between hand and leg movements, in part because our recording techniques would have obfuscated such a difference, but principally because this factor was balanced across all blocks. Accordingly we averaged across movement types and performed a $2 \times 2 \times 2$ repeated-measures
ANOVA, with factors as described below. Error rates for the different conditions were also analyzed in the same way. For the behavioral analysis, an $F$ statistic corresponding to a $p$ value of $<0.05$ was taken as a threshold for significance.

To make inferences about the spectral responses and effects of task and drug, we used Statistical Parametric Mapping (as implemented in SPM8). This treats the time-frequency matrices as images and allows the identification of regions of time-frequency space showing significant effects over subjects, while controlling for the implicit multiple comparisons using random field theory (Kilner et al., 2005).

The results of time-frequency analysis were exported to Neuroimaging Informatics Technology Initiative format and smoothed with a Gaussian smoothing kernel with full width at half maximum of $5 \mathrm{~Hz}$ by $500 \mathrm{~ms}$ for frequencies $0-100 \mathrm{~Hz}$. All the reported findings are significant with familywise error (FWE) correction at the cluster level $(p<0.01$ corrected, cluster-forming threshold $p<0.01$ uncorrected). Significant features of the mean responses were determined by subjecting mean power images across conditions to a single-sample $t$ test across subjects. Before testing for the effect of experimental conditions, we used a paired $t$ test to confirm that there was no main effect of laterality of movement (ipsilateral vs contralateral) on induced STN spectra. To test for the effects of experimental conditions, we performed repeated-measures ANOVA, treating the experiment as a $2 \times 2 \times 2$ factorial design with the factors "reward" (high vs low), "task complexity" (high vs low), and "drug" (on medication vs off medication). Using this repeated-measures design in SPM, which allows for unbalanced designs (e.g., more onmedication than off-medication recordings; Penny and Friston, 2003), we specified $t$ contrasts to test for times at which significant differences occurred using paired $t$ tests. Using the $t$ contrasts in SPM we were able to test for the direction of significance. For example, by taking the main effect of drug, we could test whether being off medication produced significantly less desynchronization than being on medication or vice versa.

We independently analyzed the spectra aligned to the onset of the warning cue, the imperative cue, and movement onset. In addition to modeling subject-specific dependencies in the recordings from the two hemispheres, we included the side as an additional categorical variable for each subject to account for potential differences between recordings from the right and left STNs.

As we were primarily interested in interpreting the significance of premovement spectral changes, an important consideration in our analysis was determining the temporal resolution of the spectral changes observed. Specifically, uncertainty in temporal estimates could be introduced by both the windowing of spectral estimation and by subsequent smoothing before statistical analysis. To further characterize the magnitude of temporal smoothing, we generated simulated data for spectral estimation, smoothing, and statistical analysis. Data from each subject were bandpass filtered in the beta $(15-35 \mathrm{~Hz})$ and gamma $(60-90 \mathrm{~Hz})$ bands and normalized by $z$ transformation. A step increase in gamma amplitude of $40 \%$ and a step decrease in beta amplitude of $40 \%$ were introduced at a known time, lasting for $0.5 \mathrm{~s}$. The resulting time series were summed and added to Gaussian random white noise to create a simulated LFP for each subject before spectral estimation and smoothing using the parameters described above. Statistical analysis was performed by subjecting the simulated data across all subjects to a one sample $t$ test and testing for positive and negative effects. These simulations suggested that spectral changes in the gamma band might be shifted to the left by $\sim 150 \mathrm{~ms}$ through windowing for spectral estimation and subsequent smoothing and by less than this in the beta band (Fig. 2).

Analysis of the EMG amplitude time series centered to movement onset (see spectral analysis for details of thresholding procedure) was also performed using the SPM pipeline with cluster level correction as described above to ensure that the muscle activations and their temporal profiles were similar for simple and complex movements. In this case, however, given that the amplitudes are vectors, the images had only a time dimension. 


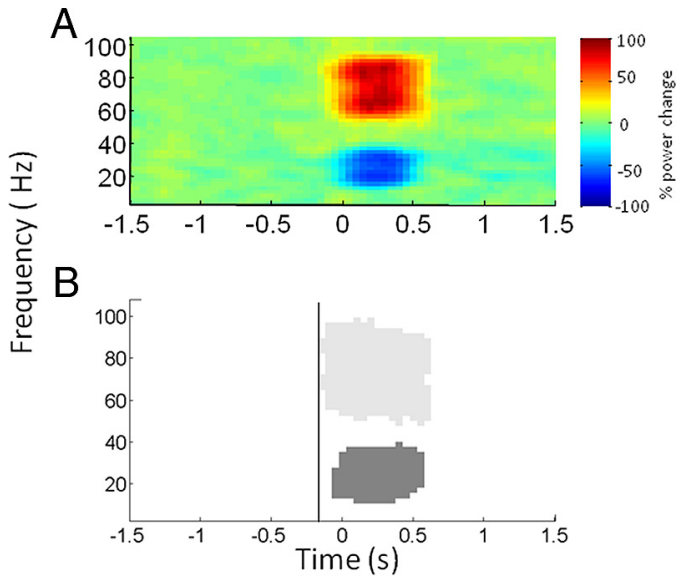

Figure 2. Mean plots of simulated data for all subjects. A step increase and decrease in gamma and beta amplitudes of $40 \%$ respectively was simulated at $0 \mathrm{~s}$ lasting for $0.5 \mathrm{~s}$. The resulting spectra were added to Gaussian random white noise. Power was determined relative to a $0.8 \mathrm{~s}$ baseline between -1.4 and $-0.6 \mathrm{~s}$. Each subject's image was smoothed with a 5 $\mathrm{Hz} \times 500 \mathrm{~ms}$ Gaussian kernel, before averaging. $A$, Spectra of the resulting time series averaged across all subjects. $\boldsymbol{B}$, Significant positive (light gray) and negative (dark gray) clusters of the mean responses in the gamma and beta bands, respectively. The vertical line at $-150 \mathrm{~ms}$ indicates that statistical changes in the gamma band can be seen as early as this despite the fact that power modulations were only introduced at $0 \mathrm{~s}$.

\section{Results}

\section{Behavioral results}

Bar charts of response latencies, averaged across subjects for the four different conditions off and on levodopa are shown in Figure $3 A$. Repeated-measures ANOVA revealed a main effect of medication, such that response times were faster on medication than off medication. Furthermore, there was a main effect of task complexity, with response times slower in low compared with high task-complexity trials. There was also an interaction between task complexity and medication, such that the shortening of response times in high task-complexity trials was more marked on medication than off medication (Table 3 ). Importantly there was no main effect of reward, or interaction of reward with any of the other factors. As it has been previously reported that STN neuronal activity may be preferentially modulated when switching from automatic to controlled movements (Isoda and Hikosaka, 2008), we investigated this in a further one-way ANOVA. Here we tested whether for high task-complexity trials there was an effect of task complexity in the preceding trial (high preceding complexity vs low preceding complexity). Our ANOVA did not reveal significant effects $\left(F_{(1,8)}=3.4, p=0.10\right)$.

Of course, reward and task complexity could potentially influence muscle responses as well as response latencies. We were able to explore this further in the lower limbs where movements were recorded with EMG (rather than button press). Here, a separate repeated-measures ANOVA of the Hilbert filtered amplitudes of high-pass filtered $(10 \mathrm{~Hz})$ EMG traces with factors medication, task complexity, and reward revealed no main effects or interactions ( $\mathrm{Ta}$ ble 3). Lower-limb EMG profiles averaged across both medication states in all subjects are shown separately for the core comparison of low versus high task-complexity trials in Figure $3 B$.

Analysis of error rates revealed no significant main effects or interactions of medication, reward, or task complexity (Table 3). The mean error rate across subjects was $16.2 \%$ with a corresponding SE of $2.1 \%$.

\section{STN LFPs}

In Figure 4, we display spectra averaged across the limbs for the eight different conditions aligned to the onset of the warning cue (Fig. 4A), to the onset of the imperative cue (Fig. $4 B$ ), and to the onset of movement (Fig. $4 C$ ). Common to the plots is a characteristic beta band desynchronization $(13-30 \mathrm{~Hz})$ and a gamma band synchronization $(60-90 \mathrm{~Hz})$ associated with movement. Movement is followed by an increase in beta power. The correspondingly aligned beta and gamma band time series were separately extracted for visualization in Figures 5 and 6, respectively.

Figures 7 and 8 show time-frequency clusters of significant statistical effects separately for data aligned to the warning cue and movement onset, respectively. In each figure, the top panel displays clusters where there was a positive effect (i.e., a power increase) of the tested main effect or interaction and the bottom panel shows clusters where there was a negative effect (i.e., a power decrease) of the tested main effect or interaction. Corresponding statistical values are provided in Table 3. In Figure 7A, the mean effect across all conditions reveals an early event-related synchronization in low frequencies $(<10 \mathrm{~Hz})$ around the time of presentation of the warning cue. In addition, episodically significant beta band suppression is evident from $0.5 \mathrm{~s}$ and covers the period up to and beyond presentation of the imperative cue. There are also late mean effects, main effects of medication and task complexity, and an interaction between medication and task complexity starting at $\sim 4 \mathrm{~s}$ and predominantly involving the beta and gamma frequency bands (Fig. 7A-D). From this figure alone it is impossible to disambiguate whether delayed effects relate to presentation of the imperative cue and preparation of the motor response or whether they reflect differences in reafferance following motor onset. Time-frequency clusters of significant statistical effects for data aligned to imperative cue presentation demonstrated that these late effects followed imperative cue onset, but still did not clarify whether they preceded the motor response (data not shown).

Realignment to movement onset, however, was more informative (Fig. 8). Mean effects show an increase in gamma and low-frequency $(<10 \mathrm{~Hz})$ power and a concomitant reduction in beta power starting before movement (Fig. 8A). Moreover, the gamma power is particularly increased with increased task complexity, starting just before movement, while the beta power is particularly decreased with increased task complexity before movement (Fig. 8C). Dopamine has an additional effect of supporting the reciprocal gamma and beta power changes in the perimovement period (Fig. $8 B$ ). Finally, there are interactions between medication and task complexity in the gamma band and in the $\alpha /$ low-beta bands around movement onset and before movement onset, respectively (Fig. 8D). In the case of the significant negative effect shown in Figure $8 D$, it was not clear looking at the spectra (Fig. 4C) whether this was solely the result of there being greater $\alpha /$ low-beta desynchronization in the high taskcomplexity trials on medication. We confirmed that this was the case by specifying $t$ contrasts to compare each of four taskcomplexity and medication conditions and showing that only the high task complexity in the on-medication condition was significantly different to any of the others. There was no main effect of reward, nor was there an interaction of reward with any other factor, in line with the behavioral data. Furthermore, as for the behavioral data, an ANOVA for high-complexity trials with preceding trial complexity as a factor revealed no significant effects (minimum cluster level FWE corrected $p=0.19$; peak $t$ statistic, 4.51). Additionally there was no significant effect of movement 
A

ON

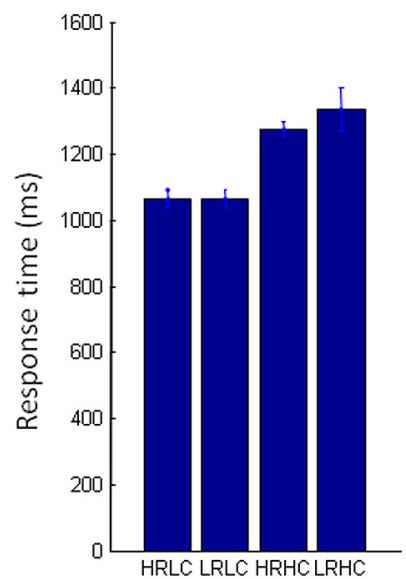

OFF

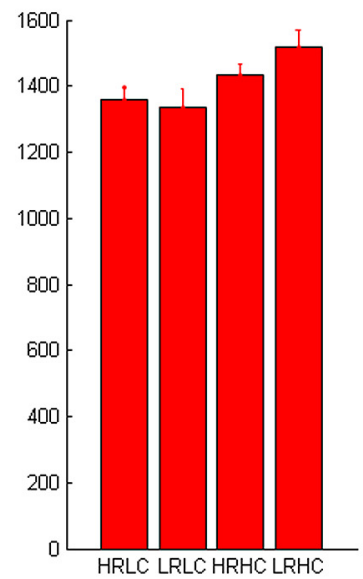

$\mathrm{B}$

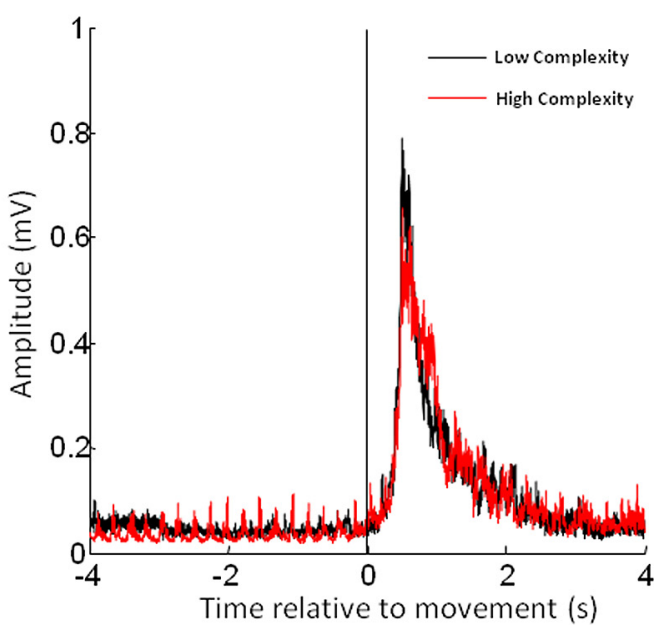

Figure 3. Behavioral data. $A$, Bar charts of response latencies averaged across upper and lower limbs and subjects for the four different conditions on and off levodopa ( \pm SE). HRLC, High reward and low complexity; LRLC, low reward and low complexity; HRHC, high reward and high complexity; LRHC, low reward and high complexity. $\boldsymbol{B}$, Hilbert amplitudes of high-pass filtered (10 Hz) tibialis anterior EMG averaged across both medication states in all subjects shown separately for the core comparison of complex versus noncomplex trials. Time 0 is onset of EMG. Note contamination of rest period with rest tremor.

Table 3. Summary of the statistical results for both behavioral and spectral data ${ }^{a}$

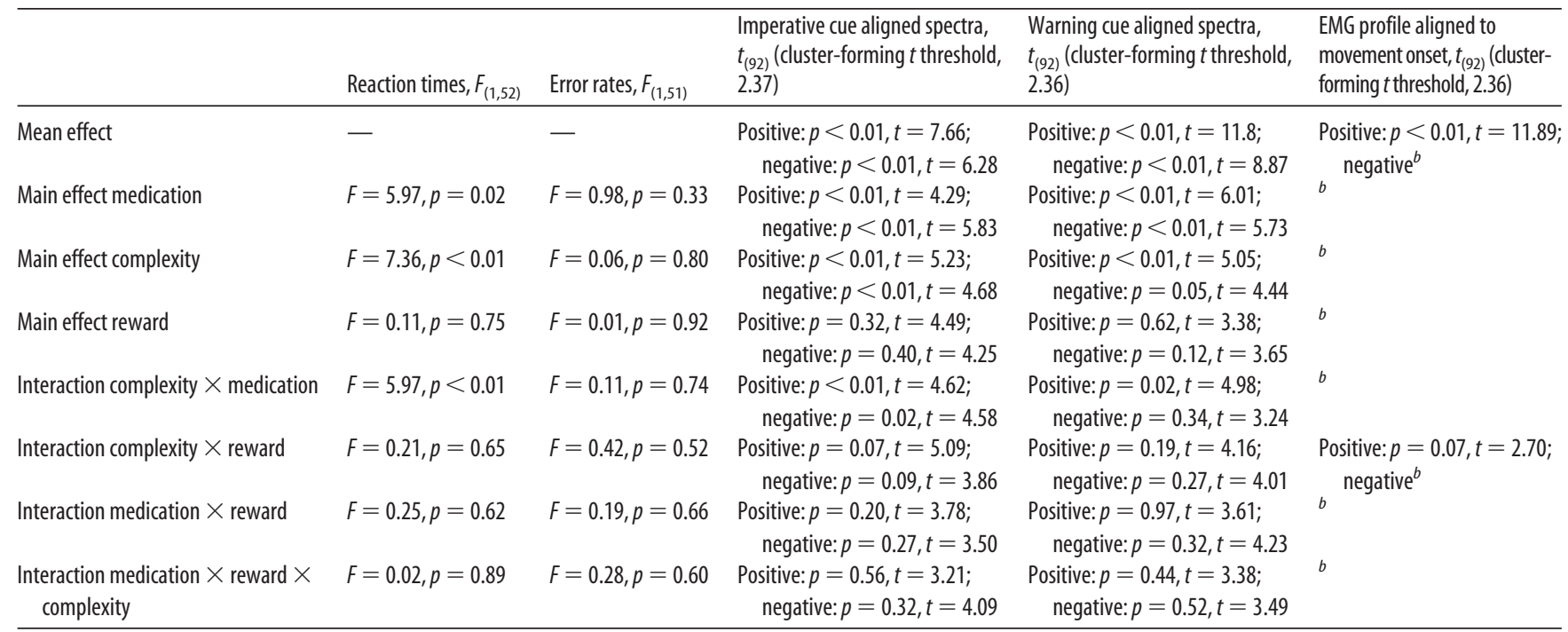

${ }^{a}$ In the case of spectral and EMG data, the cluster with the lowest FWE corrected $p$ value is reported, along with the peak $t$ value within the cluster. The statistics for each spectral test are shown representing $t$ contrasts testing for significan positive and negative changes in power (see Materials and Methods).

${ }^{b}$ No $t$ values exceeding the initial uncorrected cluster-forming threshold.

laterality on induced spectra (minimum cluster level FWE corrected $p=0.12$; peak $t$ statistic, 4.03).

The vertical gray lines in Figure 8 at -300 ms provide a conservative estimate of the uncertainty in the timing of movement onset and spectral change. Simulations suggested that spectral changes in the gamma band might be shifted to the left by $\sim 150$ $\mathrm{ms}$ through windowing for spectral estimation and subsequent smoothing (and by less than this in the beta band; Fig. 2). To this we allowed for a further $150 \mathrm{~ms}$ leftward shift to accommodate the upper-limb records where movement onset was determined from the instant of button depression rather than from EMG. Despite these allowances, mean effects, the main effects of stimulus-response compatibility, and the $\alpha /$ low-beta band interaction between stimulus-response compatibility and medication still precede movement onset (Fig. 8). Thus these changes could not be ascribed to differences in afferent feedback once movement had started. Moreover, broadly similar gamma changes were evident before and during movement, when only spectra accompanying lower-limb movements were considered (Fig. 9). In the latter case, EMG was more likely to capture the very onset of the motor response and also confirmed that there was no difference in the EMG amplitude of the response between low and high task-complexity trials (Fig. 3B). Spectra accompanying lowerlimb movements only captured a main effect of task complexity in the form of a reduction in beta activity $\sim 5 \mathrm{~s}$ before movement onset (Fig. 9D). This was rather different to the task-complexity effect in the beta band evident in spectra compiled from upper-limb and lower-limb trials (Fig. 8C, bottom), and may reflect the lower number of trials when only the lower limb was considered. 

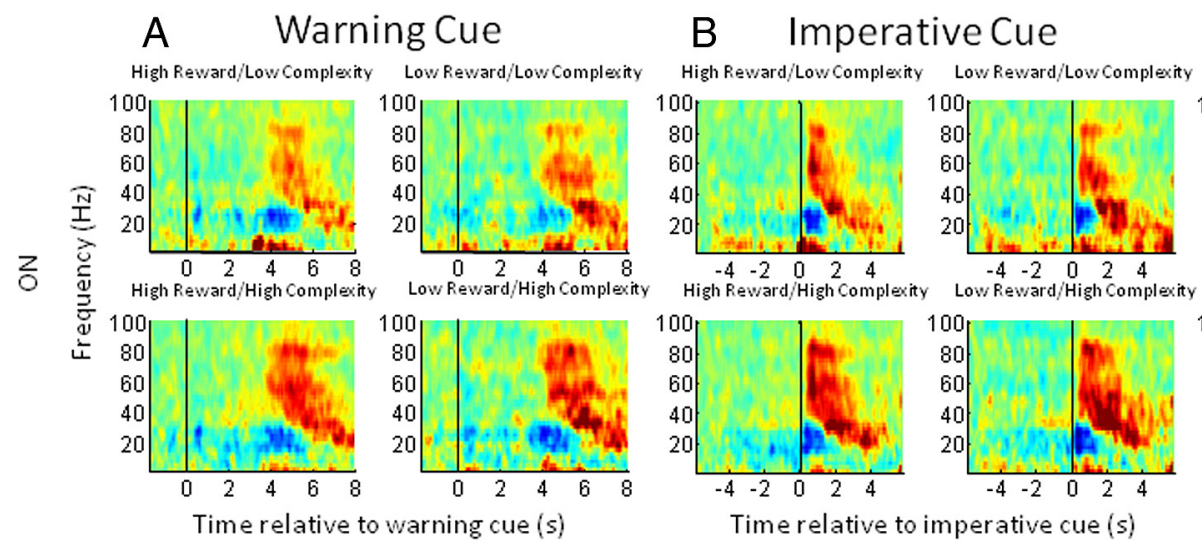

\section{Movement Onset}
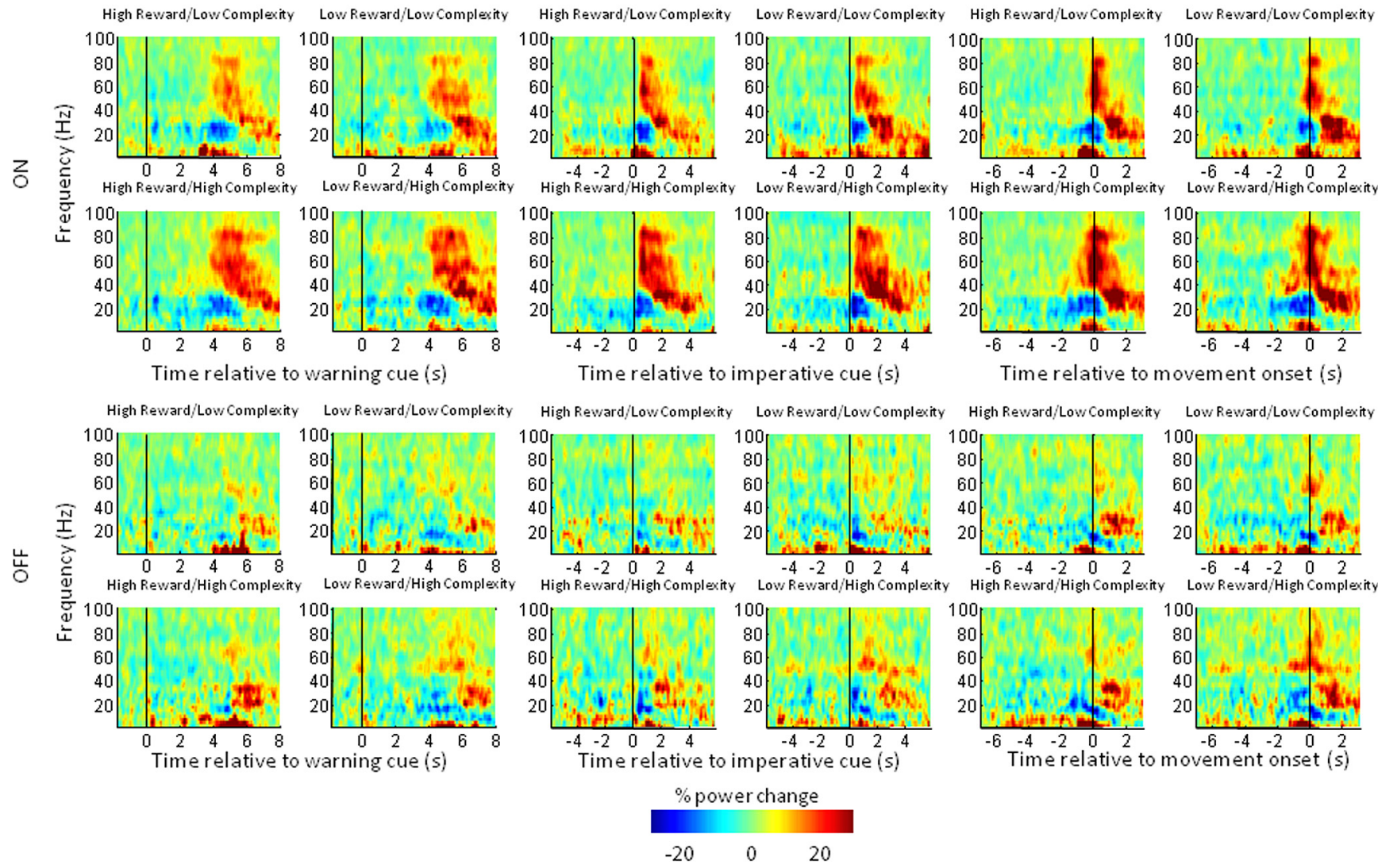

Figure 4. $\quad \boldsymbol{A}-\boldsymbol{C}$, Time-frequency plots, averaged across upper and lower limbs and all subjects, of the induced responses aligned to the onset of the warning cue $(\boldsymbol{A})$, the imperative cue $(\boldsymbol{B})$, and movement onset $(\boldsymbol{C})$ for the four different reward and trial-complexity conditions. Induced responses on and off levodopa are shown in the upper and lower halves respectively of $\boldsymbol{A}-\boldsymbol{C}$. Power was computed relative to a $0.8 \mathrm{~s}$ period before the appearance of the warning cue (see Materials and Methods) for all conditions. The main features to note are discussed in Results.

\section{Discussion}

We recorded STN LFPs to warning cues that indicated the reward and task complexity associated with an upcoming motor task. We used a paradigm where subjects were informed about these features before being told about the specific response that had to be performed. For reasons to be discussed later, reward level had no behavioral effect in the current paradigm, so we will focus discussion on the effects of task complexity, which did affect response time. In this regard, our core findings can be divided in two. As previously reported (Oswal et al., 2012), there is a task-related suppression of STN beta power when the parameters of the movement cannot be prepared in anticipation. Here we show that this effect was not modulated by prior warning of the forthcoming task complexity. This is consistent with current theories positing a specific role for beta desynchronization in signaling the likelihood of an upcoming action (Tzagarakis et al., 2010; Jenkinson and Brown, 2011), but suggests that this type of premovement beta band response does not substantially change with anticipated task demands.

In contrast, task complexity did affect processing in the STN, as evidenced by the LFP, once movement selection and preparation were possible. Critically, the effect of task complexity on LFP spectra started before movement onset. In addition, movements were, on average, the same in low and high task-complexity trials, except for response time, which was corrected for by realignment of LFP data to movement onset in the relevant analysis (Fig. 8). These two observations suggest that differences in programming of motor dynamics and peripheral reafferance are unlikely to explain the task-complexity effects.

The contrasting of the two tasks does, however, expose several different processes of interest. First, the character of the warning cue changed between blocks from a direct cue, instructing a forthcoming simple stimulus-response mapping, to a symbolic cue that provided abstract information about the need for stimulus-response remapping. However, differences in processing entailed by direct and symbolic cues would have been expected to follow these warning cues, as previously demonstrated (Yamagata et al., 2009), and yet at this point there was no effect of task complexity on the LFP nor interaction between task complexity and medication. Second, the symbolic cue might demand a proactive behavioral switching in which more automatic stimulus-response associations have to be replaced by a more controlled behavior necessary to accomplish the stimulus-response remapping. Direct recordings of neuronal activity in the STN of healthy monkeys demonstrate a clear change in discharge rates peaking just before response onset, when controlled behavior is necessary (Isoda and Hikosaka, 2008). Although changes in STN LFP and neuronal firing rate should not be considered synonymous, the switch to a more controlled processing could account for the reciprocal effects in the beta and gamma bands that became evident just before movement due to the task-complexity effect.

Thus the complexity-related effects may be due to the need for more controlled behavior entailed by active stimulus-response 

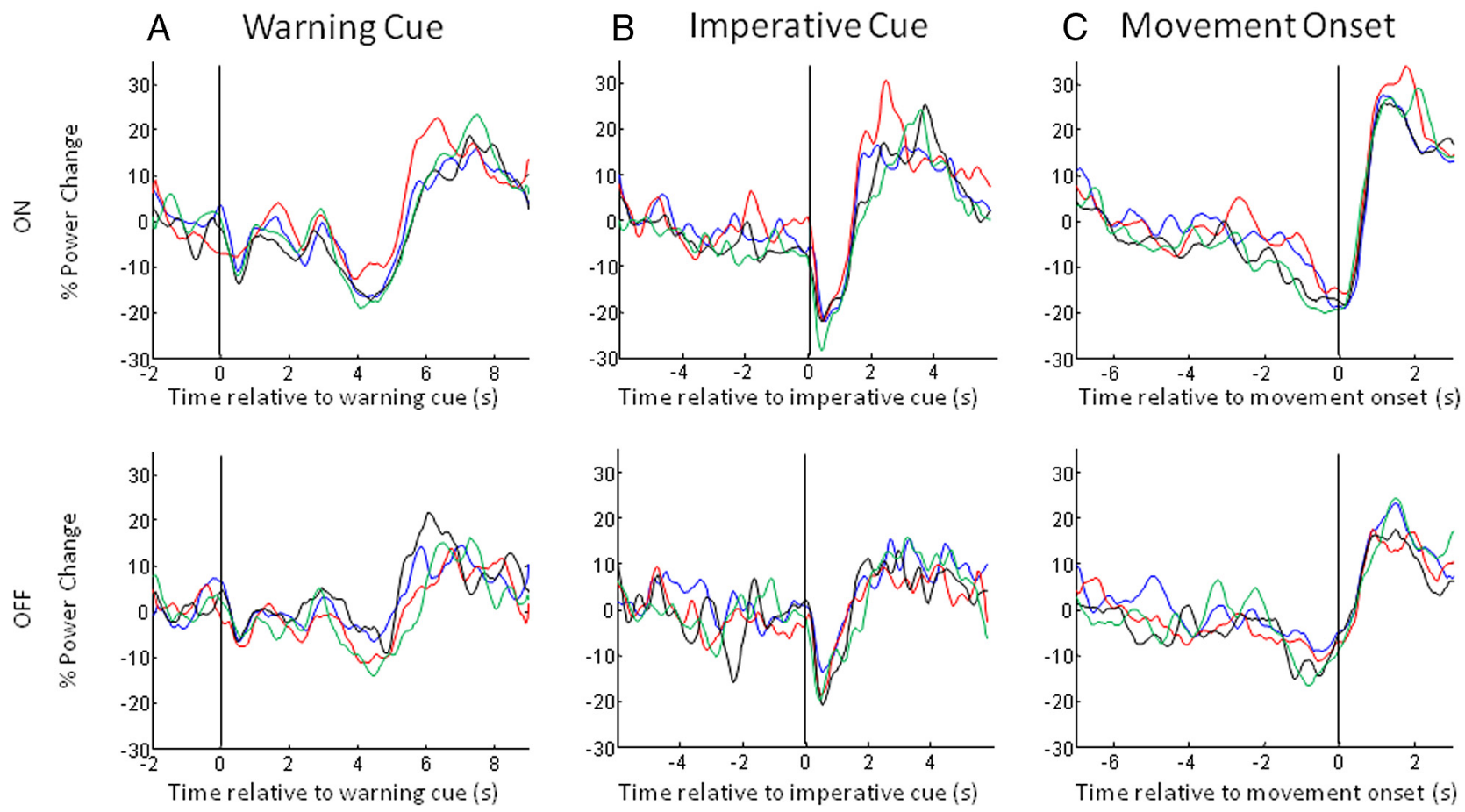

Figure 5. $\boldsymbol{A}-\boldsymbol{C}$, Mean time series of the percentage change in beta power $(15-30 \mathrm{~Hz})$ aligned to the onset of the warning cue $(\boldsymbol{A})$, the imperative cue $(\boldsymbol{B})$, and movement onset $(\boldsymbol{C})$ for the four different reward and trial-complexity conditions. The time series have been smoothed with a 10 point moving average and are plotted separately for the on-medication and off-medication states in the upper and lower panels, respectively. Note that movement-related beta desynchronization is greater on medication than off medication and there is a trial-complexity dependence of this effect such that high-complexity trials result in greater premovement desynchronization than low-complexity ones (C).

remapping. The STNs role in controlled processing is often seen as the inhibition of competing alternatives, which in this case would be the inhibition of automatic stimulus-response associations. Yet, in LFP terms, inhibitory processes in the STN, such as those captured in the Go/NoGo or Stroop paradigms, involve relative increases in beta activity rather than the task-complexityinduced exaggeration of beta suppression seen here (Kühn et al., 2004; Brittain et al., 2012). This raises the possibility that the LFP changes in the current study may relate to another feature of controlled behavior: its draw on limited, in the present context, cognitive capacity (Weingartner et al., 1984). The extent to which limited capacity is taxed can be defined as the effort made in the task, and defined in this way, effort transcends cognitive and motor domains (Lewis, 1964; Botvinick et al., 2009). Thus, it may be relevant that similar exaggerations of beta suppression and gamma synchronization in the STN are seen when explicitly motor demands are increased (Brücke et al., 2012; Tan et al., 2013b). This leads to speculation that the degree of reciprocal betagamma changes in the STN may scale with the cognitive and motor effort expended in the task. Recent models of motor control recognize the need for a general mechanism to regulate the effort expended during a task according to task demands and cost-benefit contingencies (Todorov and Jordan, 2002; Guigon et al., 2007). This function has been associated with the basal ganglia, where the function is considered to rely on dopaminergic input (Mazzoni et al., 2007; Niv and Rivlin-Etzion, 2007), in line with the interaction between dopaminergic therapy and task complexity in the current study. Although the LFP changes we describe by no means prove a role for the STN in the coding of effort, they serve to demonstrate that changes in oscillatory dynamics in the STN cannot simply be accounted for in terms of the selection and parameterization of motor variables, such as force; in our paradigm the movements made did not differ, but the resources needed to achieve them did.

Task complexity increased both gamma synchronization and beta desynchronization before and during the movement. Crucially these reciprocal effects were supported by dopamine, in keeping with the known effects of this neurotransmitter in promoting effortful behaviors (Kurniawan et al., 2011). Previous work has demonstrated that gamma activity in the basal ganglia correlates with force or velocity, but has failed to dissociate these from effort (Anzak et al., 2012; Brücke et al., 2012; Joundi et al., 2012; Tan et al., 2013a). One study explicitly contrasted simple, synchronous, and complex sequential finger movements and found no change in perimovement gamma activity in the STN (Litvak et al., 2012), although it could be argued that the demands of the complex task were less challenging than in the current paradigm.

The modulation of the depth of beta band desynchronization by task complexity once motor parameterization was possible (i.e., after the imperative cue) is also interesting. Most previous studies have reported a relatively fixed depth of beta desynchronization regardless of force or movement speed (Anzak et al., 2012; Brücke et al., 2012; Joundi et al., 2012), leading to the suggestion that beta desynchronization may act in a binary fashion to gate movement (Kühn et al., 2004; Kempf et al., 2007; Brücke et al., 2012). The present results suggest that perimovement beta desynchronization, unlike premovement anticipatory 

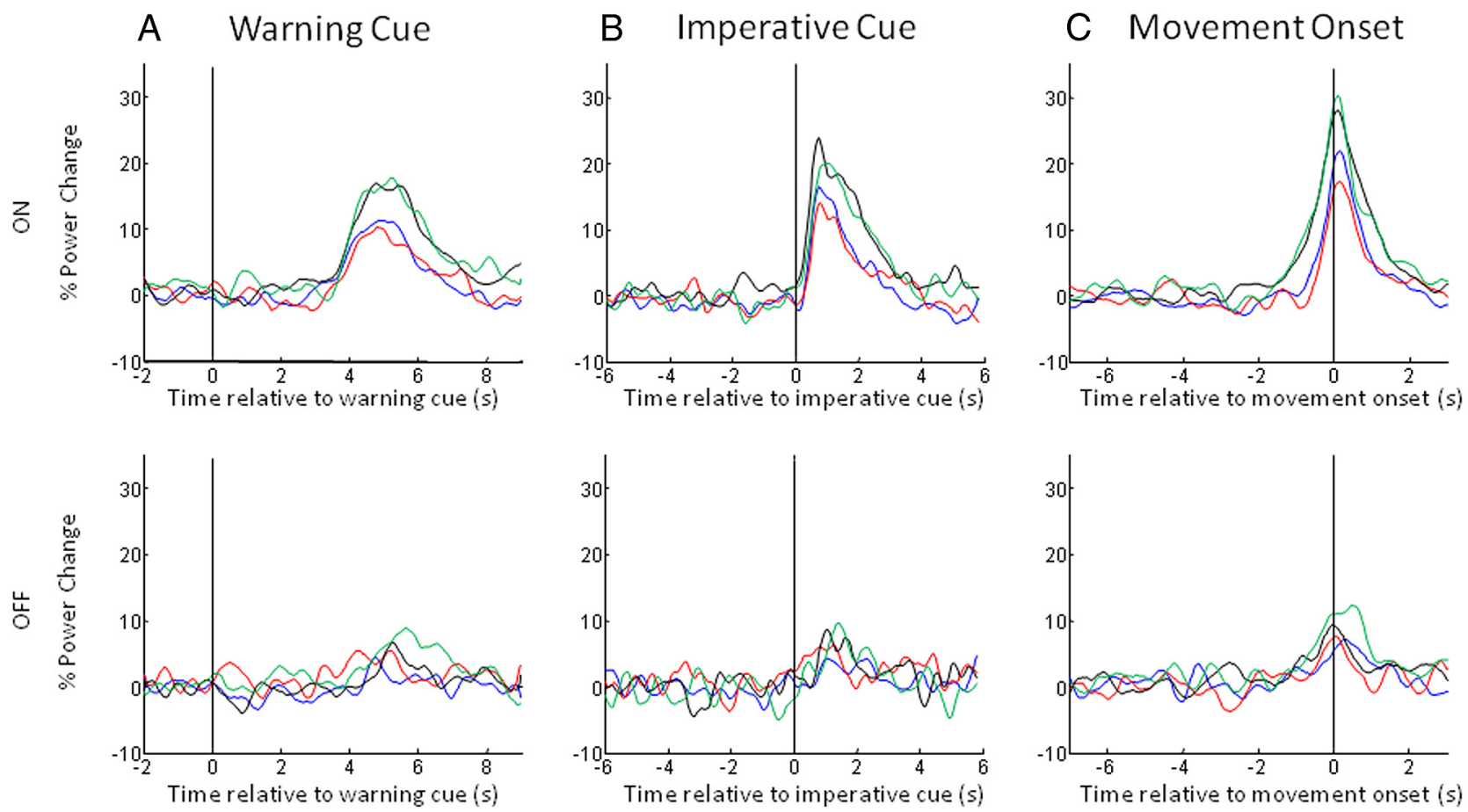

Figure 6. $A-C$, Mean time series of the percentage change in gamma power $(60-90 \mathrm{~Hz})$ aligned to the onset of the warning cue $(\boldsymbol{A})$, the imperative cue $(\boldsymbol{B})$, and movement onset $(\boldsymbol{C})$ for the four different reward and trial-complexity conditions. Movement-related gamma power synchronization is greater on medication than off medication. Movement-related gamma power increases are augmented in high-complexity trials (C).

A

Mean effect

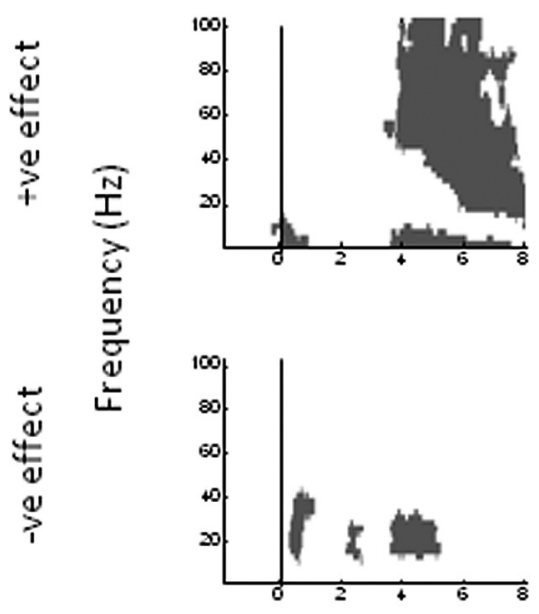

B Main effect of medication Main effect of complexity Interaction of complexity
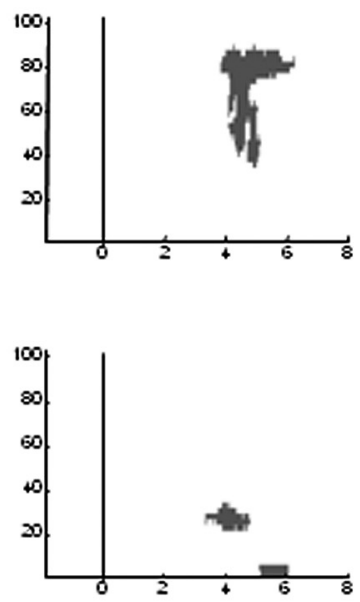
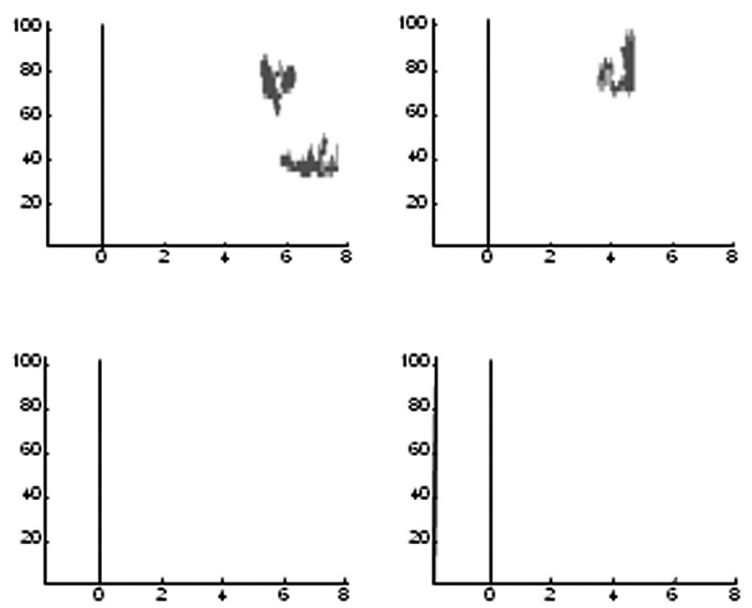

Time relative to warning cue (s)

Figure 7. Plots of significant positive (top) and negative (bottom) clusters ( $p<0.01$ cluster level FWE correction) aligned to warning cue onset. $\boldsymbol{A}-\boldsymbol{D}, t$ contrasts correspond to $(\boldsymbol{A})$ the mean overall effect across all conditions, $(\boldsymbol{B})$ the main effect of medication, $(\boldsymbol{C})$ the main effect of trial complexity, and $(\boldsymbol{D})$ the interaction between trial complexity and medication. Reward and interactions with reward were not significant at the cluster level. 
A

Me an effect

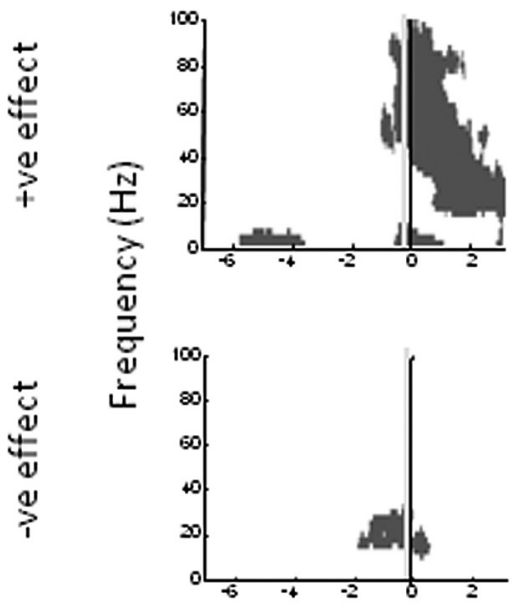

B

Main effect of medication Main effect of complexity
Interaction of complexity and medication
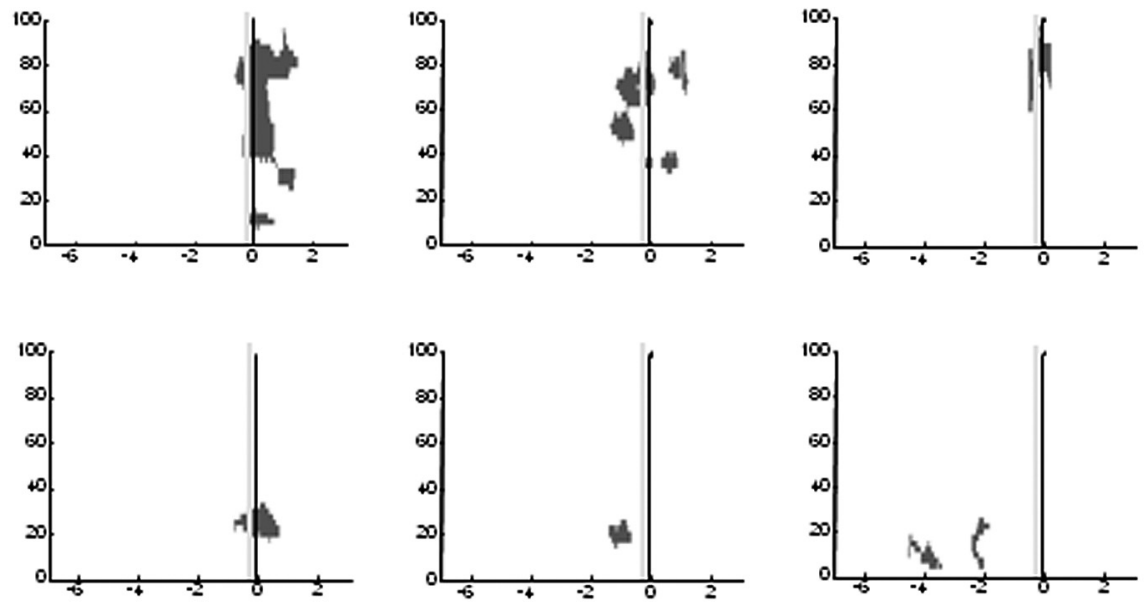

\section{Time relative to movement $(s)$}

Figure 8. Plots of significant positive (top) and negative (bottom) clusters ( $p<0.01$ cluster level FWE correction) for subject images aligned to movement onset. $A-D, t$ contrasts correspond to $(\boldsymbol{A})$ the mean overall effect across all conditions, $(\boldsymbol{B})$ the main effect of medication, ( $(\boldsymbol{C}$ the main effect of trial complexity, and $(\boldsymbol{D})$ the interaction between trial complexity and medication. Reward and interactions with reward were not significant at the cluster level. The vertical gray line in each plot indicates $-300 \mathrm{~ms}$, a conservative estimate of the uncertainty in the timing of movement onset and spectral change.

A
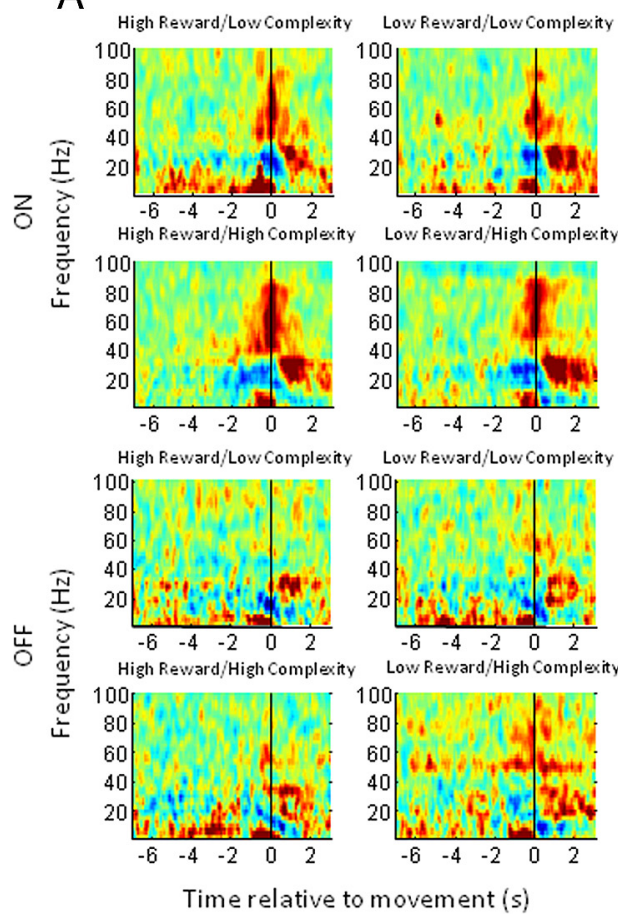

Time relative to movement (s)

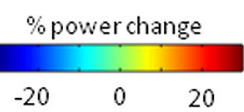

B
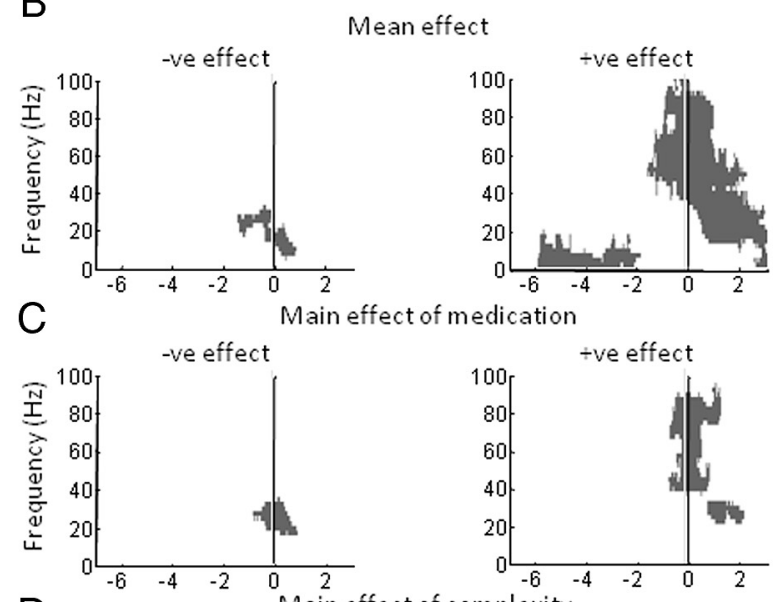

-ve effect

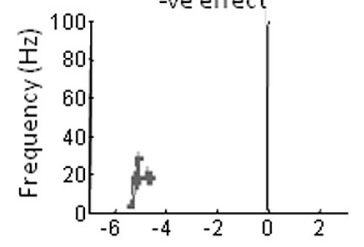

Time relative to movement (s)

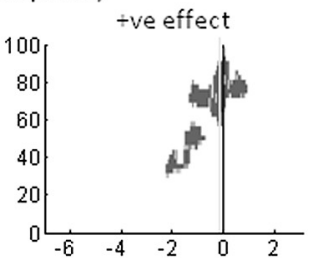

Time relative to movement (s)

Figure 9. Lower-limb data. $A$, Time-frequency plots, averaged across lower limbs and all subjects, of the induced responses aligned to the onset of movement for the four different reward and trial-complexity conditions. Induced responses on and off levodopa are shown in the upper and lower halves of panels. Power was computed relative to a $0.8 \mathrm{~s}$ period before the appearance of the warning cue. $\boldsymbol{B}-\boldsymbol{D}$, Plots of significant positive (right) and negative (left) clusters ( $p<0.01$ cluster level FWE correction) for lower-limb subject images aligned to movement onset. $t$ contrasts correspond to the mean effect $(\boldsymbol{A})$, the main effect of medication $(\boldsymbol{B})$, and the main effect of trial complexity $(\boldsymbol{C})$. The interaction between trial complexity and medication, main effect of reward and interactions with reward were not significant at the cluster level. The vertical gray lines are shown in each plot as per Figure 8, but this time at $-150 \mathrm{~ms}$ to depict the uncertainty in the timing of spectral change. 
processes in the beta band, may not be fixed but may also be modulated in tasks requiring more cognitive effort. Another recent study has suggested that the same may be true of STN beta with respect to motor effort (Tan et al., 2013b).

Our study does have several limitations. The most conspicuous was the absence of a behavioral effect of reward on response times in light of previous studies demonstrating decreased reaction times with more rewarding stimuli (Knutson et al., 2005). Likewise, error rates were no different for highly rewarded stimuli compared with lowly rewarded stimuli. Consequently, it is hard to be certain that the subjects made use of information pertaining to reward in the warning cue, perhaps through lack of reinforcement of behavioral salience in the form of post-trial reward or feedback in the current paradigm. Nevertheless, our findings are similar to those in a functional MRI study of healthy subjects in which striatal activity anticipated effort but not reward, despite, albeit limited, reward-related behavioral changes (Kurniawan et al., 2013). While previous work has demonstrated cortical beta desynchronization in parallel with reward anticipation, the magnitude of the reward was correlated with reaction time, hence confounding reward and motor processing (Doñamayor et al., 2012). Another issue is that participants were Parkinson's disease patients who had undergone surgery, so inferences with regard to normal functioning must be circumspect (Williams et al., 2002). Finally, even depth recordings of LFPs can be subject to volume conduction of cortical activities. To mitigate this, we recorded in a bipolar configuration from the contacts of the DBS electrode (Kühn et al., 2004, 2006). By demonstrating locking of STN neuronal discharge to STN LFP oscillations, other studies have provided strong evidence that STN LFP oscillations in the beta and gamma bands are locally generated (Levy et al., 2002; Kühn et al., 2005; Trottenberg et al., 2006).

In summary, we have provided evidence for two patterns of reactivity in the STN LFP in the beta band: one that is anticipatory, and has previously been linked to the likelihood of an upcoming action (Jenkinson and Brown, 2011), and one that is perimovement in timing and is partially modulated by task complexity as determined by the need for more controlled behavior and active stimulus-response remapping. The latter is complemented by a task-complexity-modulated reciprocal reactivity in the gamma band. Crucially, the effects of task complexity in increasing perimovement beta band desynchronization and gamma synchronization are potentiated by levodopa, evidenced by the bidirectional interaction between medication and task complexity. Thus, the ability to perform effortful actions may be impaired in hypodopaminergic states, such as untreated Parkinson's disease (Mazzoni et al., 2007).

\section{References}

Alegre M, Alonso-Frech F, Rodríguez-Oroz MC, Guridi J, Zamarbide I, Valencia M, Manrique M, Obeso JA, Artieda J (2005) Movement-related changes in oscillatory activity in the human subthalamic nucleus: ipsilateral vs contralateral movements. Eur J Neurosci 22:2315-2324. CrossRef Medline

Alonso-Frech F, Zamarbide I, Alegre M, Rodríguez-Oroz MC, Guridi J, Manrique M, Valencia M, Artieda J, Obeso JA (2006) Slow oscillatory activity and levodopa-induced dyskinesias in Parkinson's disease. Brain 129:1748-1757. CrossRef Medline

Androulidakis AG, Brücke C, Kempf F, Kupsch A, Aziz T, Ashkan K, Kühn AA, Brown P (2008) Amplitude modulation of oscillatory activity in the subthalamic nucleus during movement. Eur J Neurosci 27:1277-1284. CrossRef Medline

Anzak A, Tan H, Pogosyan A, Foltynie T, Limousin P, Zrinzo L, Hariz M, Ashkan K, Bogdanovic M, Green AL, Aziz T, Brown P (2012) Subtha- lamic nucleus activity optimizes maximal effort motor responses in Parkinson's disease. Brain 135:2766-2778. CrossRef Medline

Botvinick MM, Huffstetler S, McGuire JT (2009) Effort discounting in human nucleus accumbens. Cogn Affect Behav Neurosci 9:16-27. CrossRef Medline

Brittain JS, Watkins KE, Joundi RA, Ray NJ, Holland P, Green AL, Aziz TZ, Jenkinson N (2012) A role for the subthalamic nucleus in response inhibition during conflict. J Neurosci 32:13396-13401. CrossRef Medline

Brown P (2006) Bad oscillations in Parkinson's disease. J Neural Transm Suppl:27-30. Medline

Brücke C, Huebl J, Schönecker T, Neumann WJ, Yarrow K, Kupsch A, Blahak C, Lütjens G, Brown P, Krauss JK, Schneider GH, Kühn AA (2012) Scaling of movement is related to pallidal $\gamma$ oscillations in patients with dystonia. J Neurosci 32:1008-1019. CrossRef Medline

Brücke C, Bock A, Huebl J, Krauss JK, Schönecker T, Schneider GH, Brown P, Kühn AA (2013) Thalamic gamma oscillations correlate with reaction time in a Go/noGo task in patients with essential tremor. Neuroimage 75:36-45. CrossRef Medline

Carpenter RH, Williams ML (1995) Neural computation of log likelihood in control of saccadic eye movements. Nature 377:59-62. CrossRef Medline

Cassidy M, Mazzone P, Oliviero A, Insola A, Tonali P, Di Lazzaro V, Brown P (2002) Movement-related changes in synchronization in the human basal ganglia. Brain 125:1235-1246. CrossRef Medline

Devos D, Szurhaj W, Reyns N, Labyt E, Houdayer E, Bourriez JL, Cassim F, Krystkowiak P, Blond S, Destée A, Derambure P, Defebvre L (2006) Predominance of the contralateral movement-related activity in the subthalamo-cortical loop. Clin Neurophysiol 117:2315-2327. CrossRef Medline

Doñamayor N, Schoenfeld MA, Münte TF (2012) Magneto- and electroencephalographic manifestations of reward anticipation and delivery. Neuroimage 62:17-29. CrossRef Medline

Foffani G, Bianchi AM, Baselli G, Priori A (2005) Movement-related frequency modulation of beta oscillatory activity in the human subthalamic nucleus. J Physiol 568:699-711. CrossRef Medline

Fogelson N, Pogosyan A, Kühn AA, Kupsch A, van Bruggen G, Speelman H, Tijssen M, Quartarone A, Insola A, Mazzone P, Di Lazzaro V, Limousin P, Brown P (2005) Reciprocal interactions between oscillatory activities of different frequencies in the subthalamic region of patients with Parkinson's disease. Eur J Neurosci 22:257-266. CrossRef Medline

Guigon E, Baraduc P, Desmurget M (2007) Coding of movement- and force-related information in primate primary motor cortex: a computational approach. Eur J Neurosci 26:250-260. CrossRef Medline

Hammond C, Bergman H, Brown P (2007) Pathological synchronization in Parkinson's disease: networks, models and treatments. Trends Neurosci 30:357-364. CrossRef Medline

Isoda M, Hikosaka $\mathrm{O}$ (2008) Role for subthalamic nucleus neurons in switching from automatic to controlled eye movement. J Neurosci 28: 7209-7218. CrossRef Medline

Jenkinson N, Brown P (2011) New insights into the relationship between dopamine, beta oscillations and motor function. Trends Neurosci 34: 611-618. CrossRef Medline

Joundi RA, Jenkinson N, Brittain JS, Aziz TZ, Brown P (2012) Driving oscillatory activity in the human cortex enhances motor performance. Curr Biol 22:403-407. CrossRef Medline

Kempf F, Kühn AA, Kupsch A, Brücke C, Weise L, Schneider GH, Brown P (2007) Premovement activities in the subthalamic area of patients with Parkinson's disease and their dependence on task. Eur J Neurosci 25: 3137-3145. CrossRef Medline

Kilner JM, Baker SN, Salenius S, Hari R, Lemon RN (2000) Human cortical muscle coherence is directly related to specific motor parameters. J Neurosci 20:8838-8845. Medline

Kilner JM, Kiebel SJ, Friston KJ (2005) Applications of random field theory to electrophysiology. Neurosci Lett 374:174-178. CrossRef Medline

Knutson B, Taylor J, Kaufman M, Peterson R, Glover G (2005) Distributed neural representation of expected value. J Neurosci 25:4806-4812. CrossRef Medline

Kühn AA, Williams D, Kupsch A, Limousin P, Hariz M, Schneider GH, Yarrow K, Brown P (2004) Event-related beta desynchronization in human subthalamic nucleus correlates with motor performance. Brain 127: 735-746. CrossRef Medline

Kühn AA, Trottenberg T, Kivi A, Kupsch A, Schneider GH, Brown P (2005) 
The relationship between local field potential and neuronal discharge in the subthalamic nucleus of patients with Parkinson's disease. Exp Neurol 194:212-220. CrossRef Medline

Kühn AA, Doyle L, Pogosyan A, Yarrow K, Kupsch A, Schneider GH, Hariz MI, Trottenberg T, Brown P (2006) Modulation of beta oscillations in the subthalamic area during motor imagery in Parkinson's disease. Brain 129:695-706. CrossRef Medline

Kurniawan IT, Guitart-Masip M, Dolan RJ (2011) Dopamine and effortbased decision making. Front Neurosci 5:81. CrossRef Medline

Kurniawan IT, Guitart-Masip M, Dayan P, Dolan RJ (2013) Effort and valuation in the brain: the effects of anticipation and execution. J Neurosci 33:6160-6169. CrossRef Medline

Levy R, Hutchinson WD, Lozano AM, Dostrovsky JO (2002) Synchronised neuronal discharge in the basal ganglia of parkinsonia patients is limited to oscillatory activity. J Neurosci 22:2855-2861. Medline

Lewis M (1964) Effect of effort on value: an exploratory study of children. Child Dev 35:1337-1342. CrossRef Medline

Litvak V, Mattout J, Kiebel S, Phillips C, Henson R, Kilner J, Barnes G, Oostenveld R, Daunizeau J, Flandin G, Penny W, Friston K (2011) EEG and MEG data analysis in SPM8. Comput Intell Neurosci 2011:852961. CrossRef Medline

Litvak V, Eusebio A, Jha A, Oostenveld R, Barnes G, Foltynie T, Limousin P, Zrinzo L, Hariz MI, Friston K, Brown P (2012) Movement-related changes in local and long-range synchronization in Parkinson's disease revealed by simultaneous magnetoencephalography and intracranial recordings. J Neurosci 32:10541-10553. CrossRef Medline

Mazzoni P, Hristova A, Krakauer JW (2007) Why don't we move faster? Parkinson's disease, movement vigor, and implicit motivation. J Neurosci 27:7105-7116. CrossRef Medline

Niv Y, Rivlin-Etzion M (2007) Parkinson's disease: fighting the will? J Neurosci 27:11777-11779. CrossRef Medline

Oostenveld R, Fries P, Maris E, Schoffelen JM (2011) FieldTrip: open source software for advanced analysis of MEG, EEG, and invasive electrophysiological data. Comput Intell Neurosci 2011:156869. CrossRef Medline

Oswal A, Litvak V, Sauleau P, Brown P (2012) Beta reactivity, prospective facilitation of executive processing, and its dependence on dopaminergic therapy in Parkinson's disease. J Neurosci 32:9909-9916. CrossRef Medline

Oswal A, Brown P, Litvak V (2013) Movement related dynamics of subthalmo-cortical alpha connectivity in Parkinson's disease. Neuroimage 70:132-142. CrossRef Medline

Penny WD, Friston KJ (2003) Hierarchical models. In: Human brain function, 2nd edition (Frackowiak RSJ, Friston KJ, Frith C, Dolan R, Friston KJ, Price CJ, Zeki S, Penny WD, eds). San Diego: Academic.

Ponce FA, Lozano AM (2010) Deep brain stimulation state of the art and novel stimulation targets. Prog Brain Res 184:311-324. CrossRef Medline

Salamone JD, Correa M, Farrar AM, Nunes EJ, Pardo M (2009) Dopamine, behavioral economics, and effort. Front Behav Neurosci 3:13. CrossRef Medline
Samejima K, Ueda Y, Doya K, Kimura M (2005) Representation of actionspecific reward values in the striatum. Science 310:1337-1340. CrossRef

Schoffelen JM, Poort J, Oostenveld R, Fries P (2011) Selective movement preparation is subserved by selective increases in corticomuscular gamma-band coherence. J Neurosci 31:6750-6758. CrossRef Medline

Tan H, Pogosyan A, Anzak A, Foltynie T, Limousin P, Zrinzo L, Ashkan K, Bogdanovic M, Green AL, Aziz T, Brown P (2013a) Frequency specific activity in subthalamic nucleus correlates with hand bradykinesia in Parkinson's disease. Exp Neurol 240:122-129. CrossRef Medline

Tan H, Pogosyan A, Anzak A, Ashkan K, Bogdanovic M, Green AL, Aziz T, Foltynie T, Limousin P, Zrinzo L, Brown P. (2013b) Complementary roles of different oscillatory activities in the subthalamic nucleus in coding motor effort in Parkinsonism. Exp Neurol 248C:187-195. CrossRef Medline

Thomson D (1982) Spectral estimation and harmonic analysis. Proceedings of the IEEE 70:1055-1096. CrossRef

Todorov E, Jordan MI (2002) Optimal feedback control as a theory of motor coordination. Nat Neurosci 5:1226-1235. CrossRef Medline

Trottenberg T, Fogelson N, Kühn AA, Kivi A, Kupsch A, Schneider GH, Brown P (2006) Subthalamic gamma activity in patients with Parkinson's disease. Exp Neurol 200:56-65. CrossRef Medline

Turner RS, Desmurget M (2010) Basal ganglia contributions to motor control: a vigorous tutor. Curr Opin Neurobiol 20:704-716. CrossRef Medline

Tzagarakis C, Ince NF, Leuthold AC, Pellizzer G (2010) Beta-band activity during motor planning reflects response uncertainty. J Neurosci 30: 11270-11277. CrossRef Medline

Wager TD, Keller MC, Lacey SC, Jonides J (2005) Increased sensitivity in neuroimaging analyses using robust regression. Neuroimage 26:99-113. CrossRef Medline

Weingartner H, Burns S, Diebel R, LeWitt PA (1984) Cognitive impairments in Parkinson's disease: distinguishing between effort-demanding and automatic cognitive processes. Psychiatry Res 11:223-235. CrossRef Medline

Williams D, Tijssen M, Van Bruggen G, Bosch A, Insola A, Di Lazzaro V, Mazzone P, Oliviero A, Quartarone A, Speelman H, Brown P (2002) Dopamine-dependent changes in the functional connectivity between basal ganglia and cerebral cortex in humans. Brain 125:1558-1569. CrossRef Medline

Williams D, Kühn A, Kupsch A, Tijssen M, van Bruggen G, Speelman H, Hotton G, Yarrow K, Brown P (2003) Behavioural cues are associated with modulations of synchronous oscillations in the human subthalamic nucleus. Brain 126:1975-1985. CrossRef Medline

Yamagata T, Nakayama Y, Tanji J, Hoshi E (2009) Processing of visual signals for direct specification of motor targets and for conceptual representation of action targets in the dorsal and ventral premotor cortex. J Neurophysiol 102:3280-3294. CrossRef Medline 